\title{
BMJ
}

\section{Protective effect of antibiotics against serious complications of common respiratory tract infections: retrospective cohort study with the UK General Practice Research Database}

\author{
I Petersen, statistician, ${ }^{1}$ A M Johnson, head of department, ${ }^{1}$ A Islam, database manager, ${ }^{1}$ \\ G Duckworth, consultant epidemiologist, ${ }^{2}$ D M Livermore, microbiologist, ${ }^{2}$ A C Hayward, senior lecturer \\ infectious disease epidemiology ${ }^{1}$
}

UCL Centre for Infectious Disease

Epidemiology, Department of Primary Care and Population

Sciences, University College

London, London NW3 2PQ

${ }^{2}$ Health Protection Agency, Centre for Infections, London NW9 5EQ

Correspondence to: A Hayward

a.hayward@pcps.ucl.ac.uk

doi:10.1136/bmj.39345.405243.BE

\section{ABSTRACT}

Objective To determine the extent to which antibiotics reduce the risk of serious complications after common respiratory tract infections.

Design Retrospective cohort study.

Setting UK primary care practices contributing to the general practice research database.

Data source 3.36 million episodes of respiratory tract infection.

Main outcome measures Risk of serious complications in treated and untreated patients in the month after diagnosis: mastoiditis after otitis media, quinsy after sore throat, and pneumonia after upper respiratory tract infection and chest infection. Number of patients needed to treat to prevent one complication.

Results Serious complications were rare after upper respiratory tract infections, sore throat, and otitis media, and the number needed to treat was over 4000 . The risk of pneumonia after chest infection was high, particularly in elderly people, and was substantially reduced by antibiotic use, with a number needed to treat of 39 for those aged $\geq 65$ and $96-119$ in younger age groups. Conclusion Antibiotics are not justified to reduce the risk of serious complications for upper respiratory tract infection, sore throat, or otitis media. Antibiotics substantially reduce the risk of pneumonia after chest infection, particularly in elderly people in whom the risk is highest.

\section{INTRODUCTION}

Most antibiotic prescribing is in primary care, and most of it is for respiratory tract infections. ${ }^{1}$ Clinical guidelines advise against the routine use of antibiotics in patients with upper respiratory tract infection, ${ }^{23}$ sore throat, ${ }^{2}$ and otitis media. ${ }^{2}$ Guidelines divide chest infection into acute bronchitis, for which antibiotics are not recommended, and pneumonia, for which they are recommended. ${ }^{24}$ Recommendations not to prescribe are based on concerns about the development of antimicrobial resistance and evidence from meta-analyses of randomised controlled trials that have shown minimal benefits..$^{5-8}$
A national campaign in the United Kingdom targeting doctors and the public aimed to reduce unnecessary antibiotic prescribing. ${ }^{9}$ Whether in response to these campaigns or to a declining incidence of disease, rates of antibiotic prescribing for acute respiratory infections in UK general practice declined by $45 \%$ between 1994 and $2000 .^{10}$ Despite this, in 2000 antibiotics were still prescribed to $67 \%$ of patients presenting to general practice with respiratory infection, including over $90 \%$ of those with chest infection, $80 \%$ with ear infections, $60 \%$ with sore throat, and $47 \%$ with upper respiratory tract infections. ${ }^{10}$ The decisions to prescribe antibiotics are complex but on the basis of this evidence there seems to be a substantial gap between evidence based guidance and general practitioners' prescribing behaviour.

Continuing high rates of prescribing may relate to patients' expectations and to fears about serious complications of infection. ${ }^{11}$ Research has suggested that low rates of antibiotic prescribing in primary care might be associated with higher rates of complications of infection, ${ }^{12}$ and decreases in prescribing might have led to increases in mastoiditis ${ }^{13}$ and increased hospital admissions for respiratory infection in the $\mathrm{UK}^{14}$ and the United States. ${ }^{15}$ These studies cannot determine whether adverse events are occurring less frequently in those people who received antibiotics for minor infections than in those who did not. Meanwhile, randomised controlled trials generally have insufficient power to examine the effect of interventions on rare outcomes, and the patients included might not be representative of those seen in routine clinical practice.

We used a large primary care database to describe the effect of antibiotics in routine practice on the risk of serious complications after common respiratory tract infections.

\section{METHODS}

We used data from 162 practices that contributed to the UK General Practice Research Database from 1 July 1991 to 30 June 2001. In patients with common respiratory infections, we examined the risk of developing serious complications in the month after 
diagnosis of infection, excluding those that were recorded on the day of diagnosis. We calculated and compared this risk in those who were treated with antibiotics and those who were not. Patients were considered to have been prescribed an antibiotic for a respiratory tract infection if the prescription was issued on the day of the consultation. We included consultations for chest infection (excluding those in patients with a diagnosis of pneumonia at baseline), upper respiratory tract infection, sore throat, and acute otitis media based on OXMIS ${ }^{16}$ and Read ${ }^{17}$ codes (tables 1 and 2). Potentially serious complications were mastoiditis for otitis media, quinsy for sore throat, and pneumonia for chest infection and upper respiratory tract infection. In addition to these severe complications we examined the effect of antibiotics given for upper respiratory tract infection on the risk of chest infection in the subsequent month.

We used logistic regression, adjusted for age, sex, and social deprivation, to calculate odds ratios for the potential protective effect of antibiotics. Social deprivation was area based on Carstairs' $\operatorname{scores}^{18}$ for all electoral wards in England, Wales, and Scotland.

\begin{tabular}{|c|c|}
\hline Disease and Read/OXMIS codes & Description \\
\hline \multicolumn{2}{|l|}{ Mastoiditis } \\
\hline 3831 & MASTOIDITIS CHRONIC \\
\hline 3839 & MASTOIDITIS \\
\hline 3879AM & MASTOID DISEASE \\
\hline F53..00 & Mastoiditis and related conditions \\
\hline F531.00 & Chronic mastoiditis \\
\hline F531z00 & Chronic mastoiditis NOS \\
\hline F53z.00 & Mastoiditis NOS \\
\hline F55yz00 & Other middle ear or mastoid disorder NOS \\
\hline F55z.00 & Middle ear or mastoid disorder NOS \\
\hline \multicolumn{2}{|l|}{ Pneumonia } \\
\hline $481 \mathrm{~A}$ & PNEUMONIA PNEUMOCOCCAL \\
\hline $481 \mathrm{~B}$ & LOBAR PNEUMONIA \\
\hline $481 \mathrm{BA}$ & PNEUMONIA BASAL \\
\hline 485 & BRONCHOPNEUMONIA \\
\hline 486 & PNEUMONIA \\
\hline $\mathrm{H} 2 \ldots 00$ & Pneumonia and influenza \\
\hline $\mathrm{H} 21 . .00$ & Lobar (pneumococcal) pneumonia \\
\hline $\mathrm{H} 22 . .00$ & Other bacterial pneumonia \\
\hline $\mathrm{H} 22 \mathrm{z} .00$ & Bacterial pneumonia NOS \\
\hline $\mathrm{H} 25 . .00$ & Bronchopneumonia due to unspecified organism \\
\hline $\mathrm{H} 25 . .11$ & Chest infection-unspecified bronchopneumonia \\
\hline $\mathrm{H} 26 . .00$ & Pneumonia due to unspecified organism \\
\hline $\mathrm{H} 260.00$ & Lobar pneumonia due to unspecified organism \\
\hline $\mathrm{H} 261.00$ & Basal pneumonia due to unspecified organism \\
\hline \multicolumn{2}{|l|}{ Quinsy } \\
\hline $501 \mathrm{~N}$ & QUINSY \\
\hline $501 \mathrm{~PB}$ & ABSCESS PERITONSILLAR \\
\hline $501 \mathrm{PC}$ & PERITONSILLAR ABSCESS \\
\hline $501 \mathrm{TA}$ & ABSCESS TONSIL \\
\hline $2 \mathrm{DB} 5.11$ & O/E-quinsy present \\
\hline $\mathrm{H} 15 . .00$ & Peritonsillar abscess_quinsy \\
\hline H15..11 & Quinsy \\
\hline
\end{tabular}

Practices were assigned to fifths of social deprivation based on the electoral wards in which they were located. The analyses were further stratified on age if there was a significant interaction between age and antibiotic prescription. When there was a significant protective effect of antibiotics between treated and untreated patients we calculated the number needed to treat with antibiotics to prevent one patient from developing complications as $1 /$ (absolute risk difference). We also performed separate analyses of the impact of smoking and underlying chronic respiratory disease on the risk of pneumonia after chest infection and the number needed to treat. These were performed with a different set of practices selected according to the level of completeness of recording of smoking status.

\section{RESULTS}

The study included 1081000 episodes of upper respiratory tract infection, 1065088 cases of sore throat, and 459876 cases of otitis media. The risk of serious complications in the month after diagnosis of these conditions was low (table 3 ) and was significantly reduced with the use of antibiotics, but the number needed to treat to prevent one serious complication was over 4000 for all of these conditions (table 4). The protective effect of antibiotics did not vary significantly by age. We also attempted to examine acute rheumatic fever and acute glomerulonephritis as potential complications of sore throat but found that it was difficult to distinguish between acute and chronic events and that there were virtually no cases after sore throat. Therefore, we did not continue this analysis. The risk of a consultation for chest infection in the month after upper respiratory tract infection was 17 per 1000 in those not treated with antibiotics and 11 per 1000 in those who were treated (adjusted odds ratio $0.64,95 \%$ confidence interval 0.58 to 0.71 , number needed to treat $=161$ ).

There were 749389 episodes of chest infection. The risk of pneumonia in the month after diagnosis was high and was substantially reduced by antibiotics (tables 3 and 4). This effect varied significantly with age, such that the greatest protective effect was in those aged 65 and over. Without an antibiotic prescription $4 \%$ of those aged 65 and over were diagnosed with pneumonia in the month after diagnosis of a chest infection compared with $1.5 \%$ of those who were treated with an antibiotic (table 3). The number needed to treat to prevent one patient subsequently consulting with pneumonia was 39 (36 to 42) in this age group and between 96 and 119 in younger age groups (table 4). Analyses stratified by smoking status and by underlying chronic respiratory disease found no evidence that these factors affected the risk of complications or the protective effect of antibiotics.

\section{DISCUSSION}

\section{Principal findings of the study}

The risk of serious complications after sore throat, otitis media, and upper respiratory tract infection is 
Table 2 | Read and OXMIS codes used to define sore throat, upper respiratory tract infection, chest infections, and otitis media

\begin{tabular}{|c|c|}
\hline Disease and Read/OXMIS codes & Description \\
\hline \multicolumn{2}{|l|}{ Sore throat } \\
\hline 0340 & SORE THROAT STREPTOCOCCAL \\
\hline 0340A & B-HAEMOLYTIC STREPTOCOCCAL PHARYNGIT \\
\hline 0340B & SORE THROAT STREPTOCOCCAL PROVEN \\
\hline 0340BP & PHARYNGITIS STREPTOCOCCAL PROVEN \\
\hline 0340BT & STREPTOCOCCAL TONSILLITIS PROVEN \\
\hline 0340P & PHARYNGITIS STREPTOCOCCAL \\
\hline 0340PN & PHARYNGITIS SEPTIC \\
\hline 0340T & STREPTOCOCCAL TONSILLITIS \\
\hline 0799B & THROAT VIRUS \\
\hline $460 \mathrm{AN}$ & ACUTE FEBRILE NASOPHARYNGITIS \\
\hline $460 \mathrm{DN}$ & NASOPHARYNGITIS \\
\hline $460 \mathrm{RN}$ & RHINOPHARYNGITIS \\
\hline $462 \mathrm{AB}$ & PHARYNGITIS \\
\hline $462 \mathrm{AC}$ & SCRATCHY THROAT \\
\hline $462 \mathrm{AR}$ & SORE THROAT \\
\hline $462 \mathrm{AV}$ & PHARYNGITIS VIRAL \\
\hline $462 \mathrm{C}$ & ACUTE PHARYNGITIS \\
\hline $462 \mathrm{CT}$ & SORE THROAT ACUTE \\
\hline $462 \mathrm{~F}$ & PHARYNGITIS FEBRILE \\
\hline 463 & ACUTE TONSILLITIS \\
\hline $463 \mathrm{~A}$ & TONSILLITIS \\
\hline $463 \mathrm{AP}$ & PHARYNGO TONSILLITIS \\
\hline $463 \mathrm{~B}$ & FOLLICULAR TONSILLITIS \\
\hline $463 \mathrm{BC}$ & TONSILLITIS BACTERIAL \\
\hline $463 \mathrm{MP}$ & TONSILS SYMPTOMS OF \\
\hline $463 \mathrm{NF}$ & INFLAMMATION TONSIL \\
\hline $508 \mathrm{E}$ & INFECTION THROAT \\
\hline $508 \mathrm{EA}$ & ACUTE THROAT INFECTION \\
\hline 508 LD & DISCOMFORT LARYNGEAL \\
\hline $1 C 9 . .00$ & Sore throat symptom \\
\hline $1 C 9 . .11$ & Throat soreness \\
\hline $1 \mathrm{C92.00}$ & Has a sore throat \\
\hline 1C9Z.00 & Sore throat symptom NOS \\
\hline A340.00 & Streptococcal sore throat \\
\hline A340200 & Streptococcal pharyngitis \\
\hline A340300 & Streptococcal tonsillitis \\
\hline $\mathrm{H} 00 . .00$ & Acute nasopharyngitis \\
\hline H02..00 & Acute pharyngitis \\
\hline H02..11 & Sore throat NOS \\
\hline H02..12 & Viral sore throat NOS \\
\hline $\mathrm{H} 02 . .13$ & Throat infection - pharyngitis \\
\hline H024.00 & Acute viral pharyngitis \\
\hline H02z.00 & Acute pharyngitis NOS \\
\hline H03..00 & Acute tonsillitis \\
\hline H03..11 & Throat infection - tonsillitis \\
\hline H03..12 & Tonsillitis \\
\hline H031.00 & Acute follicular tonsillitis \\
\hline H035.00 & Acute bacterial tonsillitis \\
\hline H03z.00 & Acute tonsillitis NOS \\
\hline \multicolumn{2}{|l|}{ Upper respiratory tract infection } \\
\hline $460 \mathrm{~A}$ & COMMON COLD FEBRILE \\
\hline $460 \mathrm{AB}$ & COLD FEBRILE \\
\hline $460 \mathrm{~B}$ & COMMON COLD NONFEBRILE \\
\hline $460 \mathrm{BA}$ & COLD NONFEBRILE \\
\hline $460 \mathrm{D}$ & COLD (CORYZA) \\
\hline 465 & INFECTION UPPER RESPIRATORY (TRACT) \\
\hline $465 \mathrm{~A}$ & UPPER RESPIRATORY INFECTION ACUTE \\
\hline
\end{tabular}

low and the number of courses of antibiotic needed to prevent one serious complication is high (over 4000). Antibiotics for upper respiratory tract infection reduced the risk of consultation for chest infection but even without treatment less than $2 \%$ of patients consulted with a chest infection in the following month.

We found a substantial risk of pneumonia after chest infection, which was greatly reduced by antibiotic use, with a relatively low number of courses of antibiotic needed to prevent one diagnosis of pneumonia (39 in those aged 65 and over and between 96 and 119 in younger age groups). The risks of pneumonia after chest infection and the number of antibiotic courses needed to prevent one case of pneumonia were not appreciably different in smokers, those with chronic respiratory disease, or those with cardiac disease.

\section{Strengths and weaknesses of the study}

This was a large study of complications after common respiratory tract infections. The patients included in the study are probably highly representative of those seen in primary care. The cohort design allowed us to estimate the absolute risk of rare outcomes, the effect of antibiotics on this risk, and the number of antibiotic courses needed to prevent one complication.

The non-randomised design means that it is likely that patients with more severe disease will be treated with antibiotics. If those with severe disease have a higher risk of complications then this would tend to lead to an underestimation of the protective effect of antibiotics. For upper respiratory tract infection, sore throat, and otitis media the number needed to treat would be lowered but would remain high, while for chest infection this further emphasises the benefit of antibiotic prescribing.

Studies that use routine primary care databases need to rely on the Read and OXMIS codes that general practitioners have assigned to conditions. In routine practice doctors are unlikely to apply strict case definitions when allocating diagnostic codes. For example, the term "chest infection" potentially includes both acute bronchitis and pneumonia. We excluded those with a code for pneumonia at the initial consultation for chest infection but some patients probably already had undiagnosed pneumonia.

The more specific term of "acute bronchitis" was rarely coded, precluding separate analysis of this entity. In reality the only way to distinguish reliably between acute bronchitis and early pneumonia is with chest radiography. As chest radiography is not readily available in primary care there may be some misclassification of chest infection and pneumonia. This misclassification could lead to an overestimation of the risk of pneumonia after chest infection. When patients return with an unresolved chest infection there may be more pressure to prescribe and some doctors who know that guidance advises against prescription in chest infection may label the condition as pneumonia to justify their prescribing decision. This may have led to overestimation of the apparent risk of pneumonia after chest infection and the protective 


\begin{tabular}{|c|c|}
\hline $465 \mathrm{AA}$ & U R I (UPPER RESPIRATORY INFECTION) \\
\hline $465 \mathrm{~B}$ & UPPER RESPIRATORY INFECTION ACUTE VI \\
\hline H00..11 & Common cold \\
\hline H00..13 & Febrile cold \\
\hline H05...00 & Other acute upper respiratory infections \\
\hline H051.00 & Acute upper respiratory tract infection \\
\hline Ho5z.00 & Upper respiratory infect.NOS \\
\hline H05z.11 & Upper respiratory tract infection NOS \\
\hline H05z.12 & Viral upper respiratory tract infection NOS \\
\hline \multicolumn{2}{|c|}{ Chest infection } \\
\hline $466 \mathrm{BC}$ & BRONCHITIS SUBACUTE \\
\hline $466 \mathrm{C}$ & ACUTE BRONCHITIS \\
\hline $466 \mathrm{D}$ & BRONCHITIS PURULENT \\
\hline $490 \mathrm{C}$ & CHEST COLD \\
\hline 5199E & CHEST INFECTION \\
\hline H060.00 & Acute bronchitis \\
\hline H060.11 & Acute wheezy bronchitis \\
\hline H060300 & Acute purulent bronchitis \\
\hline H062.00 & Acute lower respiratory tract infection \\
\hline H06zo0O & Chest infection NOS \\
\hline H06z011 & Chest infection \\
\hline H06z100 & Lower resp tract infection \\
\hline H07..00 & Chest cold \\
\hline \multicolumn{2}{|c|}{ Otitis media } \\
\hline 3810 & ACUTE OTITIS MEDIA \\
\hline 3810ML & A L O M (ACUTE LEFT OTITIS MEDIA) \\
\hline $3810 \mathrm{MR}$ & A R O M (ACUTE RIGHT OTITIS MEDIA) \\
\hline 3810TP & OTITIS ACUTE SUPPURATIVE \\
\hline $3811 \mathrm{AR}$ & OTITIS MEDIA RECURRENT \\
\hline $3811 \mathrm{E}$ & BSOM (BILATERAL SUPPURATIVE OTITIS M \\
\hline 3819 & OTITIS MEDIA \\
\hline $3819 \mathrm{E}$ & BILATERAL OTITIS MEDIA \\
\hline 3819MP & SUPPURATIVE OTITIS MEDIA \\
\hline $3819 \mathrm{~N}$ & OTITIS \\
\hline $3819^{\mathrm{TH}}$ & HAEMOTYMPANUM \\
\hline F510.00 & Acute non suppurative otitis media \\
\hline F510000 & Acute otitis media with effusion \\
\hline F510011 & Acute secretory otitis media \\
\hline F510100 & Acute serous otitis media \\
\hline F510300 & Acute sanguinous otitis media \\
\hline F510z00 & Acute nonsuppurative otitis media NOS \\
\hline F52..00 & Suppurative otitis media \\
\hline F520.00 & Acute suppurative otitis media \\
\hline F520000 & Acute suppurative otitis media tympanic membrane intact \\
\hline F520100 & Acute suppurative otitis media tympanic membrane ruptured \\
\hline F520z00 & Acute suppurative otitis media NOS \\
\hline F524.00 & Purulent otitis media NOS \\
\hline F524000 & Bilateral supp otitis media \\
\hline F526.00 & Acute left otitis media \\
\hline F527.00 & Acute right otitis media \\
\hline F528.00 & Acute bilateral otitis media \\
\hline F52z.00 & Otitis media NOS \\
\hline
\end{tabular}

effect of antibiotics. Anecdotal evidence, however, suggests that general practitioners are unlikely to use the term pneumonia lightly as it is a serious condition.

Other biases may have led to underestimation of the risk of pneumonia. For example, pneumonia may be more likely to be treated in secondary care or during out of hours home visits and therefore under-recording may have occurred. General practitioners contributing to the database are, however, asked to record events that occur outside the surgery when they become aware of them. Several biases working in different directions may have influenced the findings, though they would need to be extreme to alter our main conclusions substantially. For sore throat, otitis media, and upper respiratory tract infection the number of antibiotic courses needed to prevent serious complications is high. For chest infection, however, the number needed to prevent one case of pneumonia is relatively modest, especially in elderly patients. Antibiotics for chest infection might also reduce the risk of other serious complications of chest infection, such as admissions to hospital for reasons other than pneumonia, but we did not assess this.

\section{Strengths and weaknesses in relation to other studies}

Observational studies using large datasets of routinely collected primary care data are the only practicable way to examine the effect of antibiotic prescribing on rare complications of common infection. Randomised controlled trials could theoretically overcome some of the biases discussed but have insufficient power and are highly selective about the patients involved. Meta-analyses have had insufficient power to examine the protective effect of antibiotics for pneumonia after upper respiratory tract infection ${ }^{7}$ or for mastoiditis after otitis media. ${ }^{5}$ With sample sizes of more than a million patients with upper respiratory tract infection (compared with 1495 participants in the metaanalysis $)^{7}$ and nearly half a million with otitis media (compared with 1669 participants in the metaanalysis), ${ }^{8}$ we were able to show that, while antibiotics have a protective effect in these conditions, the number needed to treat to prevent complications is high.

Meta-analyses have shown that antibiotics can reduce the risk of quinsy after sore throat, ${ }^{6}$ but this conclusion is primarily related to one large study in the 1950s, when the population incidence of quinsy was much higher than today. ${ }^{19}$ We included over a million cases of sore throat treated in the 1990s (compared with 10101 participants included in the meta-analysis $)^{6}$ and showed that antibiotics do indeed reduce the risk of quinsy. As with upper respiratory tract infections and otitis media, however, the number needed to treat to prevent one serious complication is high.

Our analysis focuses on the main serious complications of common respiratory infections, particularly those complications that are rare and therefore difficult to assess through randomised controlled trials or meta-analyses. We did not include length of illness, cough, days off work, or fever for this reason and also because the database includes consultations and therefore has virtually no information on these outcomes. Similarly, we have not included need for steroids in patients with asthma because this is likely to involve them taking additional doses of a previously prescribed medication that they already have at home. We have no way of assessing such use. 
Table $3 \mid$ Risk of complications in the month after diagnosis of common respiratory infections (per 10000)

\begin{tabular}{|c|c|c|c|c|}
\hline \multirow{2}{*}{$\begin{array}{l}\text { Complication after } \\
\text { infection by age (years) }\end{array}$} & \multicolumn{2}{|c|}{ Without prescription } & \multicolumn{2}{|c|}{ With prescription } \\
\hline & Risk per 10000 & No of patients & Risk per 10000 & No of patients \\
\hline \multicolumn{5}{|c|}{ Pneumonia after upper respiratory tract infection } \\
\hline $0-4$ & 10.74 & 216863 & 6.69 & 165802 \\
\hline $5-15$ & 4.45 & 98852 & 4.04 & 103866 \\
\hline $16-64$ & 6.73 & 145596 & 5.40 & 263044 \\
\hline$\geq 65$ & 53.67 & 26646 & 33.15 & 60331 \\
\hline \multicolumn{5}{|l|}{ Quinsy after sore throat } \\
\hline $0-4$ & 1.57 & 25518 & 0.42 & 95045 \\
\hline $5-15$ & 5.99 & 73429 & 5.34 & 226588 \\
\hline $16-64$ & 21.26 & 148601 & 18.37 & 449646 \\
\hline$\geq 65$ & 9.46 & 14794 & 6.04 & 31467 \\
\hline \multicolumn{5}{|c|}{ Mastoiditis after otitis media } \\
\hline $0-4$ & 1.33 & 30178 & 0.53 & 186931 \\
\hline $5-15$ & 2.39 & 16765 & 1.79 & 123032 \\
\hline $16-64$ & 11.92 & 16780 & 6.77 & 76763 \\
\hline$\geq 65$ & 13.00 & 2307 & 5.62 & 7120 \\
\hline \multicolumn{5}{|c|}{ Pneumonia after chest infection } \\
\hline $0-4$ & 125.92 & 14613 & 27.15 & 75512 \\
\hline $5-15$ & 127.31 & 5027 & 22.74 & 46612 \\
\hline $16-64$ & 116.10 & 38588 & 31.80 & 322932 \\
\hline$\geq 65$ & 402.68 & 45470 & 146.14 & 200635 \\
\hline
\end{tabular}

Many of these less serious outcomes have previously been examined by randomised controlled trials and meta-analyses that have emphasised the minimal benefits of prescribing for upper respiratory tract infection, sore throat, and otitis media. ${ }^{5-7}$ Antibiotics for upper respiratory tract infection did reduce the risk of consultations for chest infection in the following month but the number needed to treat (161) to prevent such a consultation was relatively high considering that chest infection is not a particularly serious condition. This reduction in consultation needs to be balanced against other research that has shown that prescribing for minor infections may make patients more likely to consult the next time they have such an infection. ${ }^{20}$

We identified a higher risk of pneumonia after chest infection than observed in randomised control trials for treatment of acute bronchitis. ${ }^{8}$ In such trials great care is taken to exclude pneumonia through use of

\begin{tabular}{|c|c|c|c|}
\hline $\begin{array}{l}\text { Infection/adverse outcome } \\
\text { (age group) }\end{array}$ & $\begin{array}{l}\text { Adjusted odds ratio* } \\
\qquad(95 \% \mathrm{Cl})\end{array}$ & $\begin{array}{l}\text { Number needed to treat } \\
\qquad(95 \% \mathrm{Cl})\end{array}$ & $P$ value \\
\hline URTI/pneumonia (all ages) & 0.68 (0.58 to 0.79$)$ & 4407 (2905 to 9126$)$ & $<0.001$ \\
\hline Otitis media/mastoiditis (all ages) & $0.56(0.37$ to 0.86$)$ & 4064 (2393 to 13456$)$ & 0.008 \\
\hline Sore throat/quinsy (all ages) & 0.84 (0.73 to 0.97$)$ & $4300(2522$ to 14586$)$ & 0.021 \\
\hline \multicolumn{4}{|c|}{ Chest infection/pneumonia (significant interaction between prescribing and age): } \\
\hline $0-4$ years & $0.22(0.17$ to 0.27$)$ & $101(85$ to 125$)$ & $<0.001$ \\
\hline $5-15$ years & $0.18(0.13$ to 0.24$)$ & 96 (73 to 137$)$ & $<0.001$ \\
\hline $16-64$ years & $0.27(0.23$ to 0.32$)$ & 119 (105 to 136$)$ & $<0.001$ \\
\hline$\geq 65$ years & 0.35 (0.33 to 0.38$)$ & 39 (36 to 42$)$ & $<0.001$ \\
\hline
\end{tabular}

URTI=upper respiratory tract infection.

*Adjusted for age, sex, and social deprivation. chest radiography either for all patients or all those with focal chest signs. These procedures are likely to be less stringent in routine practice. This is one of the factors likely to account for the considerably higher risk of pneumonia in our study compared with the risk in randomised control trials. Given that chest radiography is not routinely available in primary care outside the context of trials it is arguable that our findings are more pertinent to general practitioners' treatment decisions than the results of randomised control trials.

\section{Implications of the study}

There are legitimate concerns about the overuse of antibiotics in primary care and the development of resistance. For example, a recent randomised controlled trial has clearly shown increased carriage in resistant organisms after macrolide administration but not after placebo. ${ }^{21}$ General practitioners should not base their prescribing for sore throat, otitis media, or upper respiratory tract infections on a fear of serious complications. There is also broad consensus that the benefit in terms of more minor outcomes such as duration and severity of illness does not justify antibiotic use for these conditions. ${ }^{2-7}$ Nevertheless, many general practitioners continue to prescribe for these conditions. ${ }^{10}$

In contrast, antibiotics substantially reduce the risk of a diagnosis of pneumonia after chest infection. Prescribing guidance from the $\mathrm{UK}^{2}$ and the $\mathrm{US}^{4}$ recognises the difficulty in distinguishing between acute bronchitis, where doctors are advised not to prescribe antibiotics, and early pneumonia, where they are advised to prescribe. The guidance notes that in otherwise healthy, non-elderly adult patients who present with cough, pneumonia is unlikely if there are no new focal chest signs and all vital signs are normal ${ }^{24}$ and emphasises the importance of a thorough clinical examination before the decision to withhold antibiotics from patients with chest infection. Community acquired pneumonia is a serious condition with mortality ranging from $5 \%$ in ambulatory and hospitalised patients to $37 \%$ among those in intensive care. ${ }^{22}$ General practitioners already prescribe antibiotics to nearly all patients with chest infection $^{10}$ but are often criticised for doing so. We have shown that antibiotic prescribing to reduce the risk of pneumonia after chest infection is justifiable, particularly in elderly patients.

\section{Unanswered questions and future research}

We could not evaluate the effect of antibiotics on resolution of symptoms. Randomised controlled trials have consistently found these benefits to be small, ${ }^{5-8}$ and they need to be balanced against the risk of side effects and the development of antibiotic resistance. It is now unlikely that randomised controlled trials that are sufficiently large to accurately measure the protective effect of antibiotics on serious complications of common respiratory tract infection will ever be conducted. For upper respiratory tract infection, sore 


\section{WHAT IS ALREADY KNOWN ON THIS TOPIC}

Guidelines based on randomised controlled trials recommend that antibiotics should not be prescribed for upper respiratory tract infection, sore throat, or otitis media

Chest infections are divided into acute bronchitis (antibiotics not recommended) and pneumonia (antibiotics recommended)

\section{WHAT THIS STUDY ADDS}

Antibiotics reduce the risk of mastoiditis after otitis media, quinsy after sore throat, and pneumonia after upper respiratory tract infection but over 4000 courses of antibiotics are needed to prevent one complication

Conversely, the risk of pneumonia in those presenting with chest infection is high, particularly in elderly patients, and can be substantially reduced by the use of antibiotics

throat, and otitis media research should focus on effective interventions to reduce prescribing. For chest infection research should focus on developing clinical algorithms and diagnostic technology that can be easily applied in primary care to enable confident distinction between acute bronchitis and early pneumonia and to identify those who are most likely to develop pneumonia.

Contributors: ACH was chief investigator, had the original idea for the study, and developed the analytical strategy with IP. The study plan was refined with input from all authors. IP analysed the data. Al extracted the relevant data from the database. IP and ACH drafted the paper, incorporating comments from the other authors. ACH is guarantor.

Funding: Department of Health.

Competing interests: DML has various shareholdings and grants from pharmaceutical companies. AMJ has undertaken brief consultancy for GlaxoSmithKline in HPV epidemiology.

Ethical approval: GPRD scientific and ethical advisory committee.

Provenance and peer review: Not commissioned; externally peer reviewed.

1 Standing Medical Advisory Committee subgroup on antimicrobial resistance. The path of least resistance. London: Department of Health, 1998. www.advisorybodies.doh.gov.uk/SMAC/SMAC1.HTM.

2 National Prescribing Centre. The management of common infections in primary care. MeReC Bulletin 2006;17:No 3. www.npc.co.uk/ MeReC Bulletins/MeReC Bulletin_Vol17_No3 Intro.htm.

3 Pratter MR. Cough and the common cold: ACCP evidence-based clinical practice guidelines. Chest 2006;129(1 suppl):72-4S.

4 Snow V, Mottur-Pilson C, Gonzales R, American Academy of Family Physicians, American College of Physicians-American Society of Internal Medicine, Centers for Disease Control, Infectious Diseases Society of America. Principles of appropriate antibiotic use for treatment of acute bronchitis in adults. Ann Intern Med 2001;134:518-20.

5 Glasziou PP, DelMar CB, Sanders SL, Hayem M. Antibiotics for acute otitis media in children. Cochrane Database Syst Rev 2004;(1): CD000219.

6 Del Mar CB, Glasziou PP, Spinks AB. Antibiotics for sore throat. Cochrane Database Syst Rev 2006;(4):CD000023.

7 Arroll B, Kenealy T. Antibiotics for the common cold and acute purulent rhinitis. Cochrane Database Syst Rev 2005;(3):CD000247.

8 Fahey T, Smucny J, Becker L, Glazier R. Antibiotics for acute bronchitis. Cochrane Database Syst Rev 2004;(4):CD000245.

9 Department of Health. Antibiotics: don't wear me out. 1999. www.dh. gov.uk/PublicationsAndStatistics/Publications/

PublicationsPolicyAndGuidance/

PublicationsPolicyAndGuidanceArticle/fs/en? CONTENT_ID=4007460\&chk=VHEgjn.

10 Ashworth M, Latinovic R, Charlton I, Cox K, Rowlands G, Gulliford M. Why has antibiotic prescribing for respiratory illness declined in primary care? A longitudinal study using the general practice research database. J Public Health 2004;26:268-74.

11 Butler CC, Rollnick S, Pill R, Maggs-Rapport F, Stott N. Understanding the culture of prescribing: qualitative study of general practitioners' and patients' perceptions of antibiotics for sore throats. BMJ 1998;317:637-42.

12 Little P, Watson L, Morgan S, Williamson I. Antibiotic prescribing and admissions with major suppurative complications of respiratory tract infections: a data linkage study. Br J Gen Pract 2002;52:187-90.

13 Sharland M, Kendall H, Yeates D, Randall A, Hughes G, Glasziou P, et al. Antibiotic prescribing in general practice and hospital admissions for peritonsillar abscess, mastoiditis, and rheumatic fever in children: time trend analysis. BMJ 2005;331:328-9.

14 Majeed A, Williams S, Jarman B, Aylin P. Prescribing of antibiotics and admissions for respiratory tract infections in England. BMJ 2004;329:879.

15 Mainous AG 3rd, Saxena S, Hueston WJ, Everett CJ, Majeed A. Ambulatory antibiotic prescribing for acute bronchitis and cough and hospital admissions for respiratory infections: time trends analysis. I R Soc Med 2006;99:358-62.

16 Perry J. OXMIS problem codes for primary medical care. Oxford: OXMIS, 1978.

17 Chisholm J. The Read clinical classification. BMJ 1990;300:1092.

18 Carstairs V, Morris R. Deprivation and health in Scotland. Aberdeen: Aberdeen University Press, 1991.

19 Bennike TBMK, Kjaer E, Skadhauge K, Trolle E. Penicillin therapy in acute tonsillitis, phlegmonous tonsillitis and ulcerative tonsillitis. Acta Med Scand 1951;139:253-74.

20 Little P, Williamson I, Warner G, Gould C, Gantley M, Kinmonth AL. Open randomised trial of prescribing strategies in managing sore throat. BMJ 1997;314:722-7.

21 Malhotra-Kumar S, Lammens C, Coenen S, Van Herk K, Goossens H. Effect of azithromycin and clarythromycin therapy on pharyngeal carriage of macrolide-resistant streptococci in healthy volunteers: a randomised, double-blind, placebo-controlled study. Lancet 2007;369:482-90.

22 Fine MJ, Smith MA, Carson CA, Mutha SS, Sankey SS, Weissfeld LA et al. Prognosis and outcomes of patients with community-acquired pneumonia. A meta-analysis. JAMA 1996;275:134-41.

Accepted: 13 August 2007 